\title{
Applications of 3 Dimensional (3D) Printing in Biomedical Field
}

\section{IJCRR \\ Section: Healthcare \\ Sci. Journal Impact \\ Factor: 6.1 (2018) \\ ICV: 90.90 (2018) \\ (c) (i) (8) \\ Copyright@IJCRR}

\section{ABSTRACT}

Introduction: Three Dimensional (3D) printing was a daydream for various researchers and scientists. But now in today's era, this dream comes into reality. 3D printing is a rapidly growing technique in this era.

Objective: The objective of this review was to describe advanced applications of 3D printing in the biomedical field.

Methods: The methodology involves the critical review of the topic through different authentic scientific sources such as ScienceDirect, Pubmed, Google Scholar, etc. with the help of appropriate keywords.

Results: 3D system provide opportunities to medical and pharmaceutical industries to design more specific and authentic drug delivery system, high productivity of surgical and implants, more précised and personalized health care system and it is also helpful to save the life of people due to any organ failure or damage in case of any accidents or diseases. 3D printing is used to generate models, devices, surgical tools, delivery system, implants, and prostheses.

Conclusion: 3D printing has great potential for future use in the biomedical field. In future, 3D printing will bring a revolution in the health care system.

Key Words: 3 D printing, Bioprinters, Health care system, Pharmaceuticals, Prostheses, Implants

\section{INTRODUCTION}

$3 \mathrm{D}$ printing is a new technology that is adopted by the industry in the last few years. The use of 3D printing is always like a dream in the case of a medical and health care system. However, now this dream of medical and health care society came true. 3D printing is the technology in which three dimensional solid objects can be created from a digital model. 3D printing has opened the doors and areas of people associated with the medical and health care system. Now, the medical, health care and pharmaceutical companies can able to produce more rapid manufacturing of products. The quality of the product should be more specified and can be easily monitored. This technology is expanding rapidly and is expected to bring revolution in the field of medical, pharmaceutical, and health care system ${ }^{1}$. The benefits of this technology are that it leads to an easy fabrication of tissue and bones, rapid creation of models and implants, high productivity of pharmaceutical products, more specificity in drug design, and manufacturing. The challenges which are associated with $3 \mathrm{D}$ printing is that since it is very innovative and new technology so handling of such technology requires experts and the next challenge is that its compliance with the regulatory body $2,3,4$.

\section{HISTORY OF 3D PRINTING}

3D printing was invented by Charles Hull. He gave the name of "stereolithography," in the early 1980s. He was a graduate in engineering physics. Later, Hull formed a company that developed the 3D printer which is known as "stereolithography apparatus." In 1988, 3D Systems as were first commercially available which is known as SLA- $250^{5}$.

However, 3D printing becomes a platform for medical society in the early 1990s. The first time, 3D printing is used in the field of pharmaceutics where inkjet printing is used for binding of powders into the form of granules. Then the process is validated again and again till the desires shape and the

\section{Corresponding Author:}

Mrs. Archana Dhyani, Assistant Professor, School of Pharmacy, Graphic Era Hill University, Dehradun, Uttarakhand, India. Contact No.: +91-9456315495; Email: archana.dhyani89@gmail.com 
quality of product are obtained. This research first happened in the 90s at Massachusetts Institute Technology by Sachs et al. ${ }^{6}$ After that in 1989 , another patent on 3D printing was filed by Scott Crump ${ }^{7,8}$. The first 3D printing drug is approved by FDA (Food and Drug Administration) in 2016 by a US-based pharmaceutical company named Aprecia Pharmaceuticals. Inkjet printing was used to develop Spritam (levetiracetam) tablets for oral use ${ }^{7}$. The process of $3 \mathrm{D}$ printing is shown in Figure 1.

Earlier, 3D printing is utilizing in the fields of aerospace, mechanical engineering, automobile, etc. But, in recent years, the FDA motivates the use of 3D printing in the field of biomedical, pharmaceutical, and health care systems.

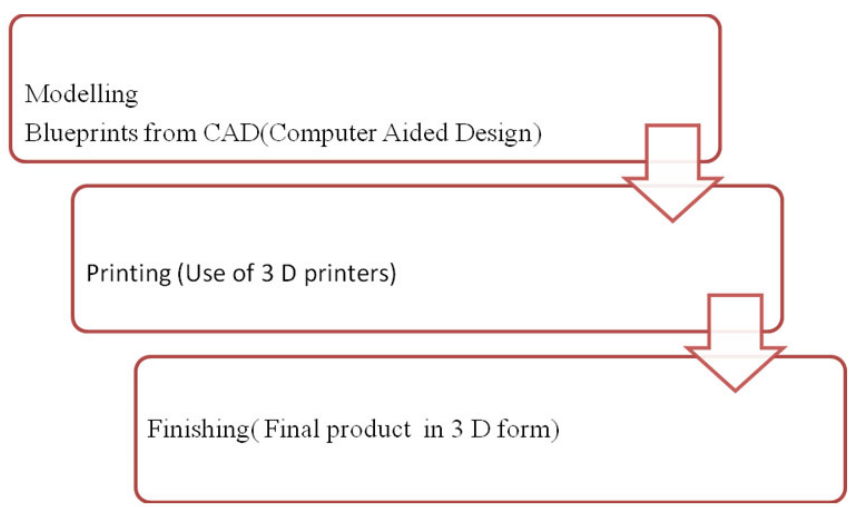

Figure 1: Process of 3D printing.

\section{REGULATORY GUIDELINES}

In the year 2017, US FDA released the guidelines on the technical aspects of using 3D printing in the biomedical field. The guidelines state that the validation of any steps and methods should be conducted to get a high level of assurance about the whole processes ${ }^{8}$.

Documentation of each step should be done so that it can be as per the compliance of all processes. All the software used in the whole process should be checked, monitored, and validated regularly. Any deviation or change in any device, methods, and processes should be documented and validated. Any deviation in the system leads to revalidation again and again ${ }^{9,10}$.

The steps involved in 3D printing of any product are that the product is designed in a 3D dosage form. The design is converted to a machine-readable format which describes the 3D surface of the dosage form. The computer program divided these layers into different layers and then it is transfers layer by layer in machine ${ }^{11-13}$.

\section{APPLICATIONS OF 3D PRINTING}

3D printing finds application in the field of biomedical from 2000 onwards. For the first time, technology is used in the fabrication of dental implants. Recently, 3D printing is used in the fabrication of bones, skeletons, ears, jaws, blood ves- sels, tissues, and organs as shown in Figure 2. The novel use of 3D printing involves tissue fabrication, implants, model fabrication, drug discovery, research, and designing of dosage forms ${ }^{14}$.

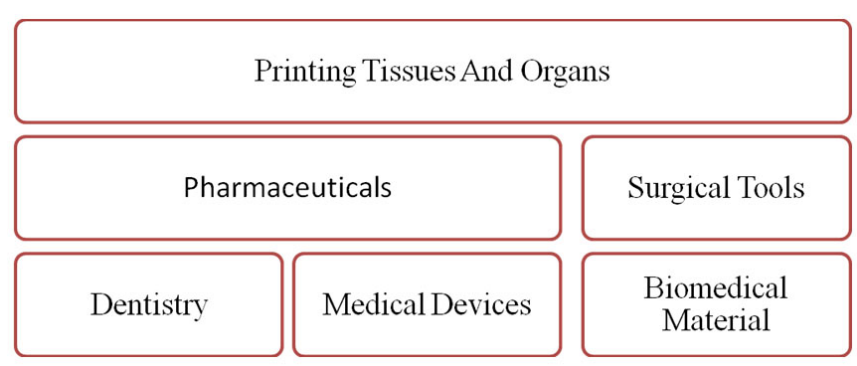

Figure 2: Applications of 3D Printing in various fields.

\section{PRINTING TISSUES AND ORGANS}

Tissue or organ failure is a major biomedical problem. The reasons for this problem include increased age, diseased states, road accidents, etc. Transplantation is not only expensive but there is also a deficiency of the organs to transplant. Further, it is very difficult to find the person who is ready to donate organs and secondly there would the chances of tissue rejection. To avoid these problems associated with tissue and organ implants the technology of tissue engineering has been explored. Rather than using conventional tissue engineering, the $3 \mathrm{D}$ printing offers various advantages like appropriate cell placement, cell concentration and size control, control on speed. 3D printing can be used in organ printing ${ }^{15}$. There are different 3D printing systems are used which includes laser-based, inkjet, extrusion-based but a part of all inkjet printing is used to produce organs and human tissues. Nowadays the researchers are using bio-printer to fabricate valves of the heart, joints, bones, spiral disk, and ear. Wang et al. produced artificial liver by depositing the different cells in hydrogels. For the fabrication of artificial liver, 3D bioprinting is used ${ }^{16}$.

\section{D PRINTING IN PHARMACEUTICALS}

The principle of 3D printing is also used in the case of drug delivery and dosage forms. The USFDA also promotes 3D printing in the development of dosage form and drug delivery. Spritam is first 3D printed pill which is produced a US-based pharmaceutical company Aprecia's by utilizing Zipdose Technology. The US-based pharmaceutical Aprecia uses Zipdose Technology for the formation of 3D printing of pill. The technology Zipdose is based on layering powder bed fusion method ${ }^{17,18}$.

Polypill: The concept of polypill is important for geriatric patients. As age is increasing the person may suffer from multiple diseases or disorders because with the increase in age the body functioning gets starts decreasing. So, there is a need for multiple drug therapy in such patients. Thus, a pa- 
tient requires a dosage form with multiple numbers of Active pharmaceutical ingredients. On the very first time Khalid et al. use five different active pharmaceutical ingredients to form a 3 dosage form. The five different API's used in the study was pravastatin, atenolol, and ramipril, aspirin, and hydrochlorothiazide. The 3D extrusion printing was utilized in the manufacturing of polypill ${ }^{19}$.

\section{TRANSDERMAL DELIVERY}

Transdermal delivery is one of the important routes of drug delivery. This is because it offers advantages like it is a noninvasive route, it bypasses the first-pass metabolism and it is more convenient than other routes of drug administration 20,21

Microneedles and transdermal patches are widely used to deliver the drugs by the transdermal route. Patches are used in transdermal drug delivery as it provides a continuous release of drug to the skin. Microneedles consist of a patch having needles like projections which are capable of penetration of drugs into the skin. In preparation of microneedles, inkjet printing is used for coating of the microneedles so that these microneedles release the drug in a controlled or sustain manner ${ }^{22}$.

\section{DRUG-RELEASING IMPLANTS}

Implants have the important and significant role in the drug delivery systems. The drug release implants are the implants that contain the biocompatible polymers in the implants and can control the release of drugs. The potential of 3D printed scaffolds for continuous drug delivery can be easily determined by conducting in-vitro studies. When the in-vitro studies conducted in 3D printed Scaffolds it shows equal effectiveness of drug release as the simple use of drugs. Thus, the 3D scaffolds can be used in the future for local drug delivery 23,24 .

\section{SURGICAL TOOLS}

Computer-Aided Design is an effective tool in the present scenario for meeting the needs and demands of the operation theatre. The 3D printed tools can be effectively used for cuts and sutures. The 3D printed tools have advantages in terms of emergencies and it is more beneficial in developing countries because of its cost-effectiveness ${ }^{25}$.

\section{IMPLANTS AND PROSTHESES}

3D printing is used in the fabrication of implants and artificial body parts such as limb, heart, breast implant. 3D implants are used in designing and fabrication of limbs, implants of dental, spiral and hip. The use of 3D printing in the field of Orthopedics opens the new door for the professionals working in this area. With the help of 3D printing, the implants and prostheses can be fabricated in time and also capable of meeting the customer's demand and acceptance ${ }^{26}$.

\section{ANATOMICAL MODELS}

Nowadays the use of 3D printed anatomical models in the surgery and other medical studies has gained popularity. This is because these models are designed in such a way that they can be easily used to determine the whole structure and functioning of any body part. Further, the surgical models can be used in place of human cadavers because the use of human cadavers is costly and the availability of such cadavers requires special attention. Similarly, the neurological models, used by a neurosurgeon are useful in demonstrating the complex structure of the human brain ${ }^{27}$. The 3D printed anatomical model of the human head and kit is shown in Figure 3.

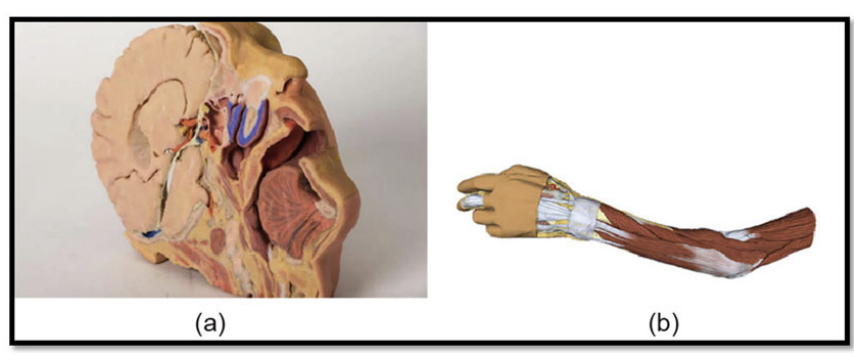

Figure 3: 3D printed human anatomical model kits, including (a) head and (b) arm, published by Monash University ${ }^{34}$ (taken from open sources)

\section{BIOMEDICAL MATERIAL IN 3D PRINTING}

The use of biomedical material such as hard metals, polymers and ceramic materials are used to fabricate biomedical implants using 3dimensional technology. 3D metal implants are used in case of orthopaedics as well as in dental implants. These are having advantages over conventional implants. Since these new implants have better mechanical performance, safe, and more convenient to use ${ }^{28}$.

\section{EDUCATING THE PATIENTS}

Patient care centre takes special care of patients in the health care system. The explanation of any condition to the patient by using a 2D CT Scan/ MRI is very difficult. So, to avoid to the difficulty of the patient to understand the 2-dimensional images (Figure 4), the 3-dimensional printing may help to increase the understanding of the patient about the 2-dimensional CT Scan/MRI ${ }^{29}$.

\section{APPLICATIONS OF 3D PRINTING IN DENTISTRY}

$3 \mathrm{D}$ printing is used by the combination of 3D CAM/CAD design and oral scanning the dental labs can easily fabricate dental crowns, models and a range of dental products. The main advantage of $3 \mathrm{D}$ printing is that it paces up the production of dental appliances productivity and production capacity $29,30,35$. 


\section{D MEDICAL DEVICES}

The production of $3 \mathrm{D}$ medical devices is increasing in the present scenario. The devices include a stethoscope, MultiSensory Perception Simulator (SPPS) device produced by the Center for Hearing and Speech in Kajetany, Poland, or $3 \mathrm{D}$ printed lenses ${ }^{31-32}$.

FDA approved the 3-dimensional printed devices Fast Forward Bone Tether Plate which is helpful in foot surgery ${ }^{33}$.

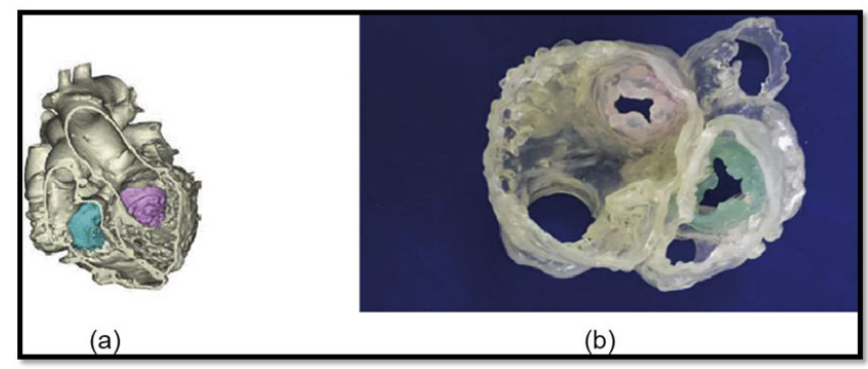

Figure 4: (a) CT scan and 3D echocardiography data model; (b) 3D printed cardiac module combining various medical imaging technologies ${ }^{34}$ (taken from open sources).

\section{CONCLUSION}

$3 \mathrm{D}$ printing had made great progress in the biomedical field. $3 \mathrm{D}$ printing has various applications in the field of biomedical sciences. The 3D printing is used for printing organs and tissues, in pharmaceuticals, medical devices, surgical tools, implants and prostheses, anatomical models, dentistry, and educating the patients. It also leads to the growth of the personalized health care system. It offers various benefits in the fabrication of tissues, models, organs, and drug design in pharmaceuticals. The ongoing studies on 3D printers and the development of novel bioprinters will amplify the growth and development of $3 \mathrm{D}$ printing. In the future the $3 \mathrm{D}$ printing will revolutionalize the whole health care system, thus $3 \mathrm{D}$ printing has a bright future.

\section{ACKNOWLEDGEMENT}

The authors are thankful to the competent authority of Graphic Era Hill University, Dehradun for providing their valuable support for the study.

\section{Conflict of Interest}

There is no conflict of interest among the authors.

Funding Source: None

\section{REFERENCES}

1. H. Arun, Healthcare 3D Printing Market 2018 ProminentPlayers-Aprecia Pharmaceuticals, Aspect Biosystems, Bio 3D
Technologies, Biobots, Cyfuse Biomedical, Digilab, 3 Dynamics Systems, Envision Tec, Luxexcel, Materialise NV, Nano 3D Biosciences, Oceanz, Organovo Ho.http://www.openpr.com. accessed date 25.05.2020

2. Banks J. Adding value in additive manufacturing: Researchers in the United Kingdom and Europe look to 3D printing for customization. IEEE Pulse 2013;4(6):22-26.

3. Mertz L. Dream it, design it, print it in 3-D: What can 3-D printing do for you? IEEE Pulse 2013;4(6):15-21.

4. Ursan I, Chiu L, Pierce A. Three-dimensional drug printing: A Structured Review. J Am Pharm Assoc 2013;53(2):136-144.

5. Gross, BC, Erkal JL, Lockwood SY. Evaluation of 3D Printing And Its Potential Impact On Biotechnology And The Chemical Sciences. Anal Chem 2014;86(7):3240-3253.

6. History of 3D Printing:The Free Beginers Guide http://cbm. msoe.edu/markMyweb/printResources/documents/history of 3D Printing. accessed date 27.05.2020

7. Wang, J, Goyanes A, Gaisford S, Basit AW. Stereolithographic (SLA) 3D printing of oral modified-release dosage forms. Int J Pharm. 2016; 503(1-2): 207-212.

8. Prasad LK, Smyth H. 3D Printing Technologies For Drug Delivery: A review. Drug Dev Ind Pharm. 2016; 42(7): 1019-31.

9. FDA Technical Consideration for Addtive Manufactured Medical Devices-Guidances for Industry and Food Drug Administration Staff,2017. https://www.fda.gov/downloads/MedicalDevices/DeviceRegulationandGuidance/Guidance Documents/ UCM499809.accessed date 26.05.2020

10. General Principles of Software validation -Guidance for Industry and Food Drug AdministrationStaff,2017.https://www. fda.gov/downloads/medicaldevices/ucm085371. accessed date 28.05.2020

11. Norman J, Madurawe R, Moore C, Khan MA, Khairuzzaman A. A New Chapter In Pharmaceutical Manufacturing: 3D-Printed Drug Products. Adv D Deli Rev. 2017; 108:39-50.

12. Diogo JH. 3D Printing of Pharmaceutical Drug Delivery Systems. Arch Org Inorg Chem Sci. 2018; 1(2):65-69.

13. Andrea AK, Marta GP, Dolores RS. Personalized 3D Printed Medicines: Which Techniques and Polymers Are More Successful?. Bioeng. 2017; 4(79) :1-16.

14. Klein GT, Lu Y, Wang MY. 3D printing and neurosurgeryready for prime time? World Neurosurg 2013;80(3-4):233-235

15. Ozbolat IT, Yu Y. Bioprinting Toward Organ Fabrication: Challenges And Future Trends. IEEE Trans Biomed Eng 2013;60(3):691-699.

16. Alhnam MA, Okwuosa TC, Sadia M, Wan K-W, Ahmed W.Emergence of 3D Printed Dosage Forms: Opportunities and Challenges. Pharm Res. 2016;33(8): 1817-1832.

17. Jassim-Jaboori AH, Oyewumi MO. 3D Printing Technology in Pharmaceutical Drug Delivery: Prospects and Challenges. Journal of Biomolecular Research and Therapeutics; 2015; 4(4): 1-3.

18. More SM, Mahajan UN, Indurwade NH, 3D printing technology: A new era in medicine. Word J Pharma Life Sci. 2018;4(4):76-83.

19. Khaled SA, Burley JC, Alexander MR, Yang J, Roberts CJ. 3D Printing Of Tablets Containing Multiple Drugs With Defined Release Profiles. Inter J Pharma. 2015; 494(2): 643-50

20. Pastore, MN, Kalia YN, Horstmann M, Roberts MS. Transdermal patches: History, Development And Pharmacology. Br. J. Pharm. 2015;172(9): 2179-2209.

21. Economidou, SN, Lamprou DA, Douroumis, D. 3D Printing Applications For Transdermal Drug Delivery. Int. J. Pharm. 2018; 544(2): 415-424

22. Haj-Ahmad R. Khan H, Arshad MS, Rasekh M, Hussain A, Walsh S, Li X, Chang MW, Ahmad Z. Microneedle Coating 
Techniques for Transdermal Drug Delivery. Pharmaceu 2015; 7(4):486-502.

23. Ahangar P, Akoury E, Ramirez Garcia Luna A, Nour A, Weber M, Rosenzweig D. Nanoporous, 3D-Printed Scaffolds for Local Doxorubicin Delivery in Bone Metastases Secondary to Prostate Cancer. Materials 2018; 11(9):1485.

24. Akoury E, Weber MH, Rosenzweig DH. 3D-Printed Nanoporous Scaffolds Impregnated With Zoledronate For The Treatment of Spinal Bone Metastases. MRS Adv. 2019, 156: 1-7.

25. Rankin TM, Giovinco NA, Cucher DJ, Watts G, Hurwitz B, Armstrong DG. Three-Dimensional Printing Surgical Instruments: Are we there yet? J. Surg. Res. 2014, 189(2):193-197.

26. Lipson H. New World Of 3-D Printing Offers "Completely New Ways Of Thinking:" Q \& A With Author, Engineer, And 3-D Printing Expert Hod Lipson. IEEE Pulse 2013;4(6):12-14.

27. Klein GT, Lu Y, Wang MY. 3D Printing And NeurosurgeryReady For Prime Time? World Neurosurg. 2013;80(3-4):233235

28. Wang M, Wu Y, Lu S, Chen T, Zhao Y. Fabrication and characterization of selective laser melting printed Ti-6Al-4V alloys subjected to heat treatment for customized implants design. Prog Nat Sci Mater Int 2016;26 (6):671-7.
29. Elenster R.10 things you need to know about 3D printing.https:// www.dentalproductsreport.com/3d-printing/11614.accessed date 25.05.2020

30. Elenster R.10 things you need to know about 3D printing..http:// www.dentalproductsreport.com/dental/article/10-things-you needknow-about-3d-printing. accessed date 28.05.2020

31. Goehrke SA. Made in Gaza: Glia Project Offers Open Source, Low-Cost, Locally 3D Printed Medical Supplies.http://3dprint. com/95097/project-gliagaza- strip/, 2015. accessed date 29.05.2020

32. 3D Printing from MRI data in 5 steps.http://www.instructables. com/id/How-to-design-3d-printed-glasses/. accessed date 30.05.2020

33. Weintraub A. 3D Systems preps for global launch of 'printed' knee implants for dogs.http://www.fiercemedicaldevices.com/ story/fda-clears-3-d-printed-device-minimally invasive-footsurgery/2015-02-02. accessed date 31.05.2020

34. Qian Y, Hanhua D, Jin S, Jianhua H, Bo S, Qingsong W, et al. A Review of 3D Printing Technology for Medical Applications. Eng 2018;4 (5): 729-742.

35. Khan A, Nag MV, MirtG, Dhiman S, Dental Image Analysis Approach Integrates Dental Image Diagnosis. IJCCR 2020;12(16):47-52. 